\title{
Congenital anomalies: the spectrum of distribution and associated maternal risk factors in a tertiary teaching hospital
}

\author{
Vinitha Wills $^{1 *}$, Jacob Abraham ${ }^{2}$, N. S. Sreedevi ${ }^{1}$ \\ ${ }^{1}$ Department of Obstetrics and Gynecology, ${ }^{2}$ Department of Paediatrics, Pushpagiri Medical College, Thiruvalla,
} Kerala, India

Received: 09 February 2017

Accepted: 07 March 2017

\section{*Correspondence:}

Dr. Vinitha Wills,

E-mail: drvinithajacob@gmail.com

Copyright: ( ) the author(s), publisher and licensee Medip Academy. This is an open-access article distributed under the terms of the Creative Commons Attribution Non-Commercial License, which permits unrestricted non-commercial use, distribution, and reproduction in any medium, provided the original work is properly cited.

\begin{abstract}
Background: To study the system-wise occurrence of congenital anomalies in newborns admitted in a tertiary hospital and to study the associated maternal factors.

Methods: This is a retrospective study of all the mothers and their newborn babies with congenital anomalies who were delivered or referred to the Obstetrical Department / Neonatology unit during a two-year study period. The maternal risk factors and associated Obstetric complications were studied.

Results: Among the babies born with congenital anomalies, the systems most involved were Genito-urinary System $(28.5 \%)$ and Cardiovascular System (20.5\%). Among the maternal risk factors, Diabetes (14.01\%), previous abortions (12.7\%) and hypothyroidism (8.7\%) were the most significant associated factors. Intrauterine growth restriction $(17.4 \%)$ was noted to be more common in these babies.

Conclusions: The incidence of anomalies was most involving the Genito-urinary System and Cardiovascular System. The major risk factor identified was maternal Diabetes. Prevention by public awareness during adolescence, preconceptional counseling and antenatal screening is stressed. Availability of Pediatric surgery and Rehabilitative facilities to improve the quality of life would be warranted.
\end{abstract}

Keywords: Congenital anomalies, Risk factors

\section{INTRODUCTION}

Congenital anomalies by a broad definition are structural or functional abnormalities including metabolic disorders which are present at birth. ${ }^{1,2}$ Morphological abnormalities arising due to structural defects or abnormal formation of tissues or organs is known as Congenital malformations. ${ }^{3}$ Fetal development is influenced by various genetic and environmental factors leading to defective embryogenesis and intrinsic abnormalities resulting in birth defects in the newborn. It is found that $2.5 \%$ of newborns are identified to have a birth malformation at birth. ${ }^{3}$ In India, congenital malformations are known to be the third common cause of perinatal mortality following infections and hypoxia ${ }^{3}$. Congenital anomalies can adversely affect the child's health and future, and also has a negative impact on the family, society and health care system.

Identification of various risk factors and modifying them can prevent these anomalies to an extent. Early antenatal diagnosis gives the clinician an option for early referral of the mother to a centre with Pediatric surgical facilities and to plan management in such babies. This study aims to identify the common fetal anomalies and various risk factors involved in order to provide baseline data for future guidelines and public health initiatives. 
The objective of the study was to frequency of various congenital anomalies system wise in newborns admitted to a tertiary neonatal facility. To identify various maternal risk factors and associated obstetrical complications present in mothers with an anomalous fetus.

\section{METHODS}

This is a retrospective study done in the Department of Obstetrics and Neonatology unit of a tertiary center. Inborn babies and babies referred with birth defects admitted in the Neonatal Intensive Care Unit (NICU) along with their mothers were the participants in this study. During the two-year study period (from June 2014- June 2016), 149 mothers gave birth to 151 babies with congenital anomalies.

This included a pair of twin babies and 2 babies of a set of triplets. Deliveries less than 26 weeks were excluded from our study. At birth, newborns were examined for presence of congenital anomalies by a neonatologist.
Diagnosis of congenital anomalies was based on clinical examination, appropriate investigations like Ultrasound, echocardiography, hematological and biochemical investigations. System wise classification of anomalies was done.

Detailed maternal and antenatal history was taken including maternal age, parity, consanguinity, bad obstetric history, medical and other obstetrical problems. History pertaining to risk factors for congenital anomalies like maternal infections, medication for medical conditions like epilepsy, diabetes, hypertension and renal disease was sought. History of substance abuse was documented. Data collected was analyzed for percentage distribution.

\section{RESULTS}

During the period from June 2014- June 2016, 149 mothers who gave birth to 151 babies with congenital anomalies, were included in the study.

Table 1: Maternal details.

\begin{tabular}{|llll|}
\hline Gravida & Primigravida & Numbers & Percentage \\
\hline & Multigravida & 76 & $51.0 \%$ \\
\hline Age & & 73 & $49.0 \%$ \\
\hline & $\leq 20$ years & 4 & $02.7 \%$ \\
\hline & $21-30$ years & 104 & $69.8 \%$ \\
\hline & $31-40$ years & 39 & $26.2 \%$ \\
\hline Period of Gestation & $>40$ years & 2 & $01.3 \%$ \\
\hline & & & \\
\hline & 28 weeks & 1 & $0.6 \%$ \\
\hline & $28-33+6$ weeks & 10 & $06.7 \%$ \\
\hline & $\geq 37$ weeks & 32 & $21.5 \%$ \\
\hline Mode of delivery & Caesarean & 106 & $71.5 \%$ \\
\hline & Term & 88 & $59.1 \%$ \\
\hline & Preterm & 57 & $38.2 \%$ \\
\hline & Vaginal & 31 & $20.8 \%$ \\
\hline & Term & 61 & $40.9 \%$ \\
\hline
\end{tabular}

$(n=149)$

There was no significant difference in parity of mothers. Multigravida mothers were 51\% (76) and primigravida were $49 \%$ (73).

Majority of mothers $69.8 \%$ (104) were of the younger age group (21-30 years). Only $26.2 \%$ (39) and $1.3 \%$ (2) belonged respectively to the $31-40$ years and above 41 age group.

Common major risk factors like consanguinous marriage and family history were not present in our study group.
Maternal risk factors seen were a history of previous abortions $12.7 \%$ (19), infertility treatment $1.3 \%$ (2), Diabetes (overt and GDM) $14.01 \% \quad$ (21). Hypothyroidism was seen in $8.7 \%$ of mothers while other medical conditions like cardiac disease and epilepsy were seen to be only $1.3 \%$ and $0.6 \%$.

Associated obstetrical problems seen in the mothers were fetal growth restriction (17.4\%), spontaneous onset of preterm labor $(10.1 \%)$, pre-eclampsia $(6.7 \%)$, malpresentations $(6.7 \%)$, anemia and abruption $1.3 \%$ each. 
Table 2: Maternal risk factors and obstetric problems.

\begin{tabular}{|c|c|c|c|c|}
\hline Risk factor & \multicolumn{2}{|c|}{ Numbers } & \multicolumn{2}{|c|}{ Percentage } \\
\hline Consanguinity & \multicolumn{2}{|l|}{-} & \multicolumn{2}{|l|}{-} \\
\hline Family history of anomalies & \multicolumn{2}{|l|}{-} & \multicolumn{2}{|l|}{-} \\
\hline History of abortions & \multicolumn{2}{|l|}{19} & \multicolumn{2}{|l|}{$12.7 \%$} \\
\hline History of Intra-Uterine Foetal Death & \multicolumn{2}{|l|}{-} & \multicolumn{2}{|l|}{-} \\
\hline Infertility treatment & \multicolumn{2}{|l|}{2} & \multicolumn{2}{|l|}{$1.3 \%$} \\
\hline Anti-epileptic drugs & \multicolumn{2}{|l|}{1} & \multicolumn{2}{|l|}{$0.6 \%$} \\
\hline Rh Negative & \multicolumn{2}{|l|}{6} & \multicolumn{2}{|l|}{$4.0 \%$} \\
\hline Maternal infections & \multicolumn{2}{|l|}{-} & \multicolumn{2}{|l|}{-} \\
\hline Cardiac disease & \multicolumn{2}{|l|}{2} & \multicolumn{2}{|l|}{$1.3 \%$} \\
\hline Anemia & \multicolumn{2}{|l|}{2} & \multicolumn{2}{|l|}{$1.3 \%$} \\
\hline Hypothyroid & 13 & & \multicolumn{2}{|l|}{$8.7 \%$} \\
\hline Diabetes Overt diabetic & \multirow[t]{2}{*}{21} & 2 & $14.0 \%$ & $1.3 \%$ \\
\hline Gestational Diabetes melitis & & 19 & & $12.7 \%$ \\
\hline Pre-eclampsia & \multicolumn{2}{|l|}{10} & \multicolumn{2}{|l|}{$6.7 \%$} \\
\hline Polyhydraminios & \multicolumn{2}{|l|}{1} & \multicolumn{2}{|l|}{$0.6 \%$} \\
\hline Oligohydramnios & \multicolumn{2}{|l|}{3} & \multicolumn{2}{|l|}{$2.0 \%$} \\
\hline Foetal growth restriction & \multicolumn{2}{|l|}{26} & \multicolumn{2}{|l|}{$17.4 \%$} \\
\hline Foetal malpresentation & \multicolumn{2}{|l|}{10} & \multicolumn{2}{|l|}{$6.7 \%$} \\
\hline Abruptio placentae & \multicolumn{2}{|l|}{2} & \multicolumn{2}{|l|}{$1.3 \%$} \\
\hline Preterm labour* & 15 & & $10.1 \%$ & \\
\hline
\end{tabular}

$(n=149) *$ Patients who came with spontaneous preterm labor and does not include those that needed termination early for other obstetrical reasons.

Table 3: Baby details.

\begin{tabular}{|c|c|c|c|c|}
\hline \multicolumn{5}{|l|}{ Maturity } \\
\hline \multicolumn{2}{|l|}{ Preterm } & \multicolumn{2}{|l|}{42} & $27.8 \%$ \\
\hline \multicolumn{2}{|l|}{ Term } & \multicolumn{2}{|l|}{109} & $72.2 \%$ \\
\hline \multicolumn{5}{|l|}{ Gender } \\
\hline \multicolumn{2}{|l|}{ Male } & \multicolumn{2}{|l|}{91} & $60.3 \%$ \\
\hline \multicolumn{2}{|l|}{ Female } & \multicolumn{2}{|l|}{59} & $39.1 \%$ \\
\hline \multirow{2}{*}{\multicolumn{5}{|c|}{$\begin{array}{l}\text { Ambigous } \\
\text { Birth weight (grams) }\end{array}$}} \\
\hline & & & & \\
\hline \multirow[t]{3}{*}{$<2500$} & $<1499$ & 8 & \multirow{3}{*}{$\begin{array}{l}54 \\
(35.76 \\
\%)\end{array}$} & $05.3 \%$ \\
\hline & $1500-1999$ & 14 & & $09.3 \%$ \\
\hline & $2000-2499$ & 32 & & $21.2 \%$ \\
\hline \multirow{3}{*}{$2500-4000$} & $2500-2999$ & 46 & \multirow{4}{*}{$\begin{array}{l}91 \\
(60.26 \\
\%)\end{array}$} & $30.5 \%$ \\
\hline & $3000-3499$ & 32 & & $21.2 \%$ \\
\hline & $3500-3999$ & 13 & & $08.6 \%$ \\
\hline$>4000$ & & 6 & & $03.9 \%$ \\
\hline
\end{tabular}

$(\mathrm{n}=151$

There were $27.5 \%$ (42) preterm babies and term babies were $72.5 \%$ (109). Among the preterm babies, $21.5 \%$ (32) were late preterms (34-37 weeks), while the remaining were early preterms $6.7 \%$ (10) with one baby $<28$ weeks. Preterm babies were those who had either come and delivered after spontaneous onset of preterm labor or iatrogenically terminated in view of other obstetrical indications.
Mode of termination was Cesarean $59.1 \%$ (88) and vaginal mode of delivery occurred in $40.9 \%$ (61). Cesarean was mainly done for obstetric indications like previous Cesarean and malpresentations. Among the newborns, $60.3 \%$ (91) were male babies and $39.1 \%$ (59) were female. One baby was found to have genital ambiguity.

Most common system affected in the newborns was genitourinary system $28.5 \%$ (43), and cardiovascular system $20.5 \%$ (31). Other systems affected were 
musculoskeletal $11.9 \% \quad$ (18), CNS $11.9 \% \quad$ (18), Respiratory system 8.6\% (13), GIT 9.3\% (14) and other minor defects constituted about $19.2 \%$ (29).
There were $35.5 \%$ (54) babies of low birth weight $(<2500$ grams) of which $5.3 \%$ (8) were very low birth weight babies $(<1.5 \mathrm{~kg})$. Large for gestational age babies $(>4 \mathrm{~kg}$ ) were $3.9 \%(6)$.

Table 4: Classification of Congenital Anomalies system-wise.

\begin{tabular}{|lll|}
\hline System & No of babies & Percentage \\
\hline Musculo-skeletal & 18 & $11.9 \%$ \\
\hline CNS & 18 & $11.9 \%$ \\
\hline Gastro-intestinal system & 14 & $9.3 \%$ \\
\hline Genito-urinary system & 43 & $28.5 \%$ \\
\hline Cardio-vascular system & 31 & $20.5 \%$ \\
\hline Respiratory system & 13 & $8.6 \%$ \\
\hline Multisystem & 04 & $2.6 \%$ \\
\hline Miscellaneous & 29 & $19.2 \%$ \\
\hline
\end{tabular}

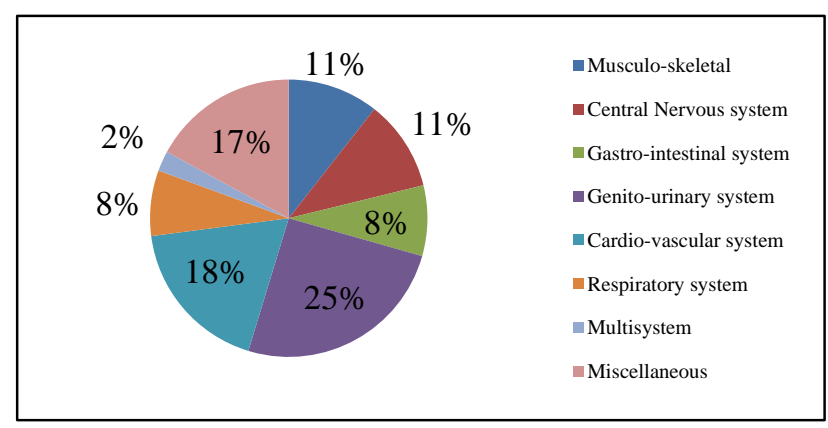

Fig. 1 Diagrammatical representation of congenital anomalies system-wise

\section{DISCUSSION}

The WHO reports 3-7\% of newborns every year with major congenital anomalies world-wide. ${ }^{4-7}$ In the West, malformations constituted $30-50 \%$ of neonatal deaths. ${ }^{3}$

Prevalence of congenital anomalies vary from country to country due to the various racial, socio-cultural and ethnic influence. ${ }^{8}$ In the Middle East where consanguinous marriage is common, the prevalence of congenital anomalies is $2-2.5 \%$. A high prevalence ocongenital anomalies $(7.0 \%)$ was noted in families with consanguinity there. ${ }^{4}$ In England and US, the prevalence is $2 \%$ and $2-3 \%$ respectively. ${ }^{9}$ Higher usage of alcohol, cigarettes and substance abuse in the Western population could explain this similarity in occurrence there where consanguinity was rare. Very few women in our society are exposed to these teratogenic factors. Literature proves that higher maternal age is a risk factor for congenital anomalies. It is supported further by evidence of advanced maternal age being associated with chromosomal abnormalities in the fetus. Studies by Swain, Savaskar and Parmar noted the highest incidence of birth defects in mothers more than 35 years of age 10-13. However only $26.2 \%$ (39) mothers were above 31 years in this study and $69.8 \%$ (104) mothers were in the 21- 30-year age group (Table 1).

Swain, Savaskar and Padma observed that congenital anomalies were more in multigravida than in primigravidae. ${ }^{11,12,14}$ It was significantly seen to be higher in mothers of gravida ${ }^{4}$ or more. ${ }^{11,15,16}$ This study had $51 \%$ of primigravida and $49 \%$ of multigravida mothers having babies with anomalies without any such noted predominance.

Savaskar and Verma mentioned anemia, hydramnios and a history of previous abortion to be associated in mothers with anomalous babies. ${ }^{12,17}$ Other risk factors observed in these studies were infections in first the trimester, medication use and preeclampsia. Gupta observed anemia $(0.96 \%)$, previous abortions $(1.98 \%)$, preeclampsia $(3.9 \%)$, oligohydramnios $(5.12 \%)$ and polyhydramnios $(11.7 \%)$ in mothers with anomalous babies. ${ }^{18}$

In this study, the common obstetric problems identified were IUGR (17.4\%), preeclampsia (6.7\%), malpresentations $(6.7 \%)$, oligohydramnios $(2.0 \%)$ and polyhydramnios $(0.6 \%)$. A case control analysis over 20 years in the West reported Gestational Diabetes Mellitus, pre-existing Diabetes and maternal renal disease to be associated more with renal anomalies in the fetus 19 . Other Western studies also report Diabetes especially overt Diabetes to be a major risk factor for Congenital Anomaly of Kidney and Urinary Tract (CAKUT) 20(Table 2).

Gupta reported $28.5 \%$ of diabetic mothers with anomalous babies especially cardiovascular problems. ${ }^{18}$ Our study had only $1.3 \%$ of overt diabetic mothers while $12.7 \%$ of mothers had gestational diabetes and another $12.7 \%$ had history of previous abortions. Other important risk factors like antiepileptic treatment, maternal cardiac disease and infertility were only $0.6 \%, 1.3 \%$ and $1.3 \%$ respectively. 
Congenital malformations are known to be a cause of preterm labour. Studies by Prajapati, Patel and Aman Taskade showed a significantly higher incidence of anomalies in preterm babies than term babies. ${ }^{10,21,22}$ This study had more of term babies $72.18 \%$ (109), while preterm babies were only $42(27.8 \%)$. Among the preterm babies in this study, $21.50 \%$ were late preterms (34-37 weeks) while $6.70 \%$ were early preterms (Table 3 ).

Among 151 babies with multiple anomalies, the most common system affected was the genito-urinary system $28.5 \%$ (43) followed by cardiovascular malformation $20.5 \%$ (31) (Table 4 and Figure1). Other systems affected were musculoskeletal and Central Nervous System (CNS) problems $11.9 \%$ (18) each. Abnormalities in respiratory system and Gastro Intestinal system were $8.6 \%$ (13) and $9.3 \%$ (14) respectively. There were 2 babies with Down syndrome, a case each of Sirenomelia and popliteal pterygeal syndrome- all having multisystem involvement. A large number $19.25 \%$ (29), could not be specifically classified. They were conditions like accessory nipple (8), cleft palate (10), single umbilical artery (7), pre-auricular tag (2) and 1 each with microtia and amniotic band syndrome.

Genito-urinary system anomalies were the common malformation that was observed in our study population, whereas Gupta found an incidence of $6.4 \% .^{18}$ The commonest anomaly they found was CNS malformations (41.9\%). His findings were similar to that of Mashuda who noted $29.8 \%$ and Francine who had $16.6 \%$ of CNS malformations in their respective studies. ${ }^{4,23}$

There were $35.7 \%$ (54) babies who were Low Birth Weight $(<2500 \mathrm{gm})$ of which $5.3 \%$ (8) were Very Low Birth Weight $(<1500 \mathrm{gm})$. There were $3.9 \%$ (6) babies who were Large for Gestational Age (>4000 gm) (Table 3 ). Congenital anomalies are suspected and much more common in Low birth weight babies whose mothers do not have any explainable antenatal risk factor for growth retardation.

\section{Preventive strategies}

Awareness in the public regarding congenital anomalies in the fetus and the possible etiologies including environmental and genetic factors should be there. Educating adolescents and mothers is the best strategy. Counseling them regarding the pitfalls of late motherhood, consanguinous marriages, radiation and substance abuse is necessary. Ensuring prior rubella vaccination, screening for diabetes and pre-conceptional blood sugar control along with adequate intake of iodine, iron and folic acid also helps. ${ }^{24}$

Pre-conceptional counseling and screening of high risk mothers with maternal serum markers, procedures like amniocentesis, chorionic villus sampling should be done, thus helping in early diagnosis of anomalies. ${ }^{24}$ This makes it possible for the family to come to terms with it, consider options if necessary of pre-natal fetal therapy or termination of pregnancy. After delivery, examination of a newborn by trained person is required for early diagnosis and referral. Screening of newborns for gross morphological abnormalities, pulse oxymetry for cardiac anomalies and blood tests for congenital hypothyroidism should be done. Screening for other inborn errors of metabolism may be considered in indicated cases ${ }^{24,25}$.

Medical, surgical treatment, rehabilitation and palliative care can also help improve the outcome in these children. In-utero therapy, while more common in the West is yet to catch up in India.

\section{CONCLUSION}

Incidence of anomalies was most involving the Gentiourinary system and cardiovascular systems. Major risk factor identified was diabetes with fetal growth restriction as the most common associated obstetrical problem.

A preventive approach by the health services, medical fraternity and the community is the only way to bring down the incidence of birth defects. Screening of the foetus during the antenatal period and the newborn at birth is required for early diagnosis and further management.

\section{Funding: No funding sources}

Conflict of interest: None declared

Ethical approval: The study was approved by the Institutional Ethics Committee

\section{REFERENCES}

1. Sarkar S, Patra C, Dasgupta MK, Nayek K, Karmakar PK. Prevalence of Congenital Anomalies in Neonates and Associated Risk Factors in a tertiary care hospital in Eastern India. J Clin Neonatol. 2013; 2(3):131-4.

2. Park K. Preventive medicine in Obstetrics, Pediatrics and Geriatrics. In: Park's Textbook of Preventive and Social Medicine.: Banarsidas Bhanot Publishers. 23rd Edition.2015;577.

3. Slavotinev A. Dysmorphology. In: Kliegman, Stanton, St, editors. Nelson Textbook of Pediatrics. Vol I. 1st South Asia Edition. Elsevier;899-909.

4. Mashuda F, Zuechner A, Chalya PL, Kidenya BR, Manyama M. Pattern and factors associated with congenital anomalies among young infants admitted at the Bugando Medical Centre, Mwanza, Tanzania. BMC Research Notes. 2014 7:195.

5. Howson CP, Christianson AC, Modell B. Controlling birth defects: reducing the hidden toll of dying and disabled children in low-income countries. Dis Control Prior Proj. 2008.

6. Singh A, Gupta RK. Pattern of congenital anomalies in newborn: a hospital based prospective study. JK Sci. 2009,1:34-6. 
7. Sekhobo JP, Druschel CM. An evaluation of congenital malformations surveillance in New York State: an application of Centres for Disease Control and Prevention (CDC) guidelines for evaluating surveillance systems. Public Health Rep. 2001. 116:296-305.

8. Birch MR, Grayson N, Sullivan EA. AIHW Cat. No. PER 23. Birth Anomalies Series No. 1. Sydney: AIHW National Perinatal Statistics Unit. Recommendations for development of a new Australian birth anomalies system: A review of the congenital malformations and birth defects data collection. 2004.

9. Biri A, Onan A, Korucuoglu Ü, Tiras B. Birth prevalence and distribution of congenital anomalies in a university hospital. Perinatol Dergisi. 2005; 13:86-90.

10. Prajapati VJ, Kacha AR, Kakkad KM, Damor PB, Nandaniya AM. Study of congential malformations in neonates born at tertiary care hospital. Natl J Community Med. 2015;6(1):30-34.

11. Swain S, Agarwal A, Bhatia BD. Congenital malformation at birth, Indian Pediatrics 1994; 31:1187-91.

12. Savaskar SV, Mundada SK, Pathan AS, Gajbhiye SF. Study of various antenatal factors associated with congenital anomalies born at tertiary health centre. International Journal of Recent Trends in Science and Technology. 2014;12(1):82-5.

13. Parmar A, Rathod SP, Patel SV, Patel SM. Study of Congenital Anomalies in Newborn. NJIRM. 2010;1(1):13-17.

14. Padma S, Ramakrishna D, Jijiya P, Ramana PV. Pattern of distribution of congenital anomalies in still born: a hospital based prospective study. International Journal of Pharma and Bio-sciences. 2011:2(2).

15. Mohanty C, Mishra OP, Das BK, Bhatia BD, Singh G. Congenital malformations in newborns: A study of 10,874 consecutive births. J Anat Soc India 1989,38:101-11.

16. Kulshreshtha R, Nath LM, Upadhyaya P. Congenital Malformation in live born infants in a rural community. Indian Pediatr. 1982.19:1003-9.

17. Verma M, Chhatwal J, Singh D. Congenital malformations - a retrospective study of 10,000 cases. Indian J Pediatr. 1991;58:245-52.

18. Gupta S, Gupta P, Soni JS. A study on incidence of various systemic congenital malformations and their associations with maternal factors. National Journal of Medical Research. 2012;2(1).

19. Shnorhavorian M, Bittner R, Wright JL, Schwartz SM. Maternal risk factors for congenital urinary anomalies: results of a population-based case-control study. Urology. 2011;78(5):1156-61.

20. Dart AB, Ruth CA, Sellers EA, Au W, Dean HJ. Maternal diabetes mellitus and congental anomalies of the kidney and urinary tract (CAKUT) in the child. Am J Kidney Dis. 2015;65(5):684-91.

21. Patel ZM, Adhia RA. Birth defect surveillance study. Indian J Pediatrics. 2005;2:489-90.

22. Taskade A. Congenital malformation at birth in central India. A rural medical college based data. Indian Journal of Human Genetics 2010;16:159-63.

23. Francine R, Pascale S, Aline H. Congenital anomalies: Prevalence and Risk factors. University Journal of Public Health. 2014;2(2):8-63.

24. Birth Defects: Report by the Secretariat. World Health Organization. Sixty-Third World Health Assembly;2010.

25. Shamnas M, Arya PS, Thottumkal VA, Deepak MG. Congenital anomalies: a major public health issue in India. International Journal of Pharmaceutical, Chemical and Biological Sciences. IJPCBS. 2013, 3(3),577-85.

Cite this article as: Wills V, Jacob A, Sreedevi ns. Congenital anomalies: The spectrum of distribution and associated maternal risk factors in a tertiary teaching hospital. Int J Reprod Contracept Obstet Gynecol 2017;6:1555-60. 